confident, and appreciation of alert responsiveness.

Lastly, you may be asked if there are any questions you wish to ask the committee. However, you should already have gathered the information that you need, and should avoid asking a question merely for the sake of doing so. Further, this is certainly not the best place to ask about money. leave, or other personal considerations that may occur to you. This may suggest lack of real interest in, or commitment to the job.

Having stressed the importance of preparation and rehearsal in the avoidance of 'bad luck', I would like to conclude on a different note. A good interview, whether in the consulting room or in the committee chamber, must combine preparedness with spontaneity and naturalness. You will destroy rapport with a patient if you hustle him through a list of questions and similarly you will appear glib and inauthentic if you approach an interviewer with a list of stock responses. It is impossible, of course, to prepare to be natural and spontaneous, but it is possible to allow these qualities to emerge by removing some of the anxiety and lack of forethought that may stifle budding success.

REFERENCES

'RHodes. P. (1983) Letters to a young doctor. British Medical Journal, 286, 618: 706: 784 .

${ }^{2}$ STEWART, R. H. M. (1971) The art of being interviewed. Lancet, i, 127-29.

\title{
The Use of Film in Psychiatry
}

\author{
Thomas L. Pilkington, Honorary Lecturer, Department of Psychiatry, University of Leeds
}

The magic lantern was first demonstrated in 1660 by Christian Huygens, a Dutch physicist, and by the 18th century 'moving' slides were being shown, as in Robertson's 'Phantasmagoria' in 1798. At the same time dissolving slides, using more than one lantern, and optical toys, based on persistence of vision, were being displayed. The resynthesis of motion recorded as photographic images was first carried out by Eudweard J. Muybridge in 1879 , using twenty-four cameras and trip wires to photograph a moving horse. The development of flexible light-sensitive film, in association with an intermittent movement and shutter. anticipated the inauguration of the public cinema in 1896 .

Film was being shown at medical and surgical conferences by the turn of the century and its scientific use was considerably enhanced by the introduction of non-flammable $16 \mathrm{~mm}$ film by Mees in 1923. The potentials of Super $8 \mathrm{film}$. launched in 1965, were never fully exploited due to the more impressive technical developments made in television recording since that time. The records of the BMA's film library show that the production of psychiatric films finally reached its peak in the 1960 s.

The commercial cinema has produced many films with a mental health content and even in 1913 over fifty films in the Pathe film library in Paris were said to be of some psychiatric interest. With the development of the cinema as a political force in the 1930s, especially in Germany. and as a propaganda medium in the 1940s, the relevance of cutting, camera angles. sound reinforcement and other cinematic techniques to arousal. empathy and conditioning became more appreciated and sophisticated. Entertainment films have also been shown to have value in psychiatric teaching: Annear ${ }^{t}$ used The Seventh Veil (psychoneurosis). Through a Glass Darkly (schizophrenia), Frenzy (psychopathy), Lolita (psychosexual). Who's Afraid of Virgiania Woolf? (alcoholism) and The War Game (disasters) for this purpose.

An early pioneer in the use of film in psychiatry was Gesell
$(1934)^{2}$ who recorded child development at Yale through a oneway vision dome. At the same time Lewin ${ }^{3}$ used film to study children's reactions to their environment, although the grasping and Babinski reflexes of babies had been recorded much earlier by Watson in 19214 and Gilbreth' had used films for time and motion studies before the First World War. In the 1930s the clinical features of schizophrenia, paranoia and other psychoses were being recorded by Leighton ${ }^{\circ}$ and in the early post-war years Lehmann' continued this aspect in his Mental Symptoms series made with the National Film Board of Canada.

Specific therapies were well represented. In the early 1940 s Patterson $^{8}$ filmed modified ECT and Freeman and Watts ${ }^{9}$ recorded the operation of leucotomy. In 1944 Fitzgerald and Loginotto ${ }^{10}$ made a film on insulin coma therapy, and in the same year Moreno" explored the therapeutic uses of film, as later did Müller and Bader ${ }^{12}$ by getting patients to make a movie as part of group therapy. Prados ${ }^{13}$ was also using film for psychotherapy at about this time.

Film had been found to be of special value in studies of children. In the late 1940s Spitz ${ }^{14}$ recorded the first reactions of the new-born and Robertson ${ }^{15}$ (1952) commenced his studies of children in separation. Other uses were being explored at about this time. Fulgham and Pasternack ${ }^{16}$ used motion pictures as a double-blind technique in a drug trial and Cornelison and Arsenian ${ }^{17}$ studied the response of psychotic patients to photographic self-image experience. In Paris Duché and Duvivier ${ }^{\prime *}$ were creating artistic interpretations of psychotic conditions on film and Margaret Mead ${ }^{19}$ was continuing her use of film in anthropological studies. Appraisal of the actual impact of film was comparatively neglected, atthough $L y n n^{20}$ had attempted to measure facial responses to stimulation by film, and this aspect was further explored in the 1940 s in a large-scale survey by Mary Field (Director of the Children's Film Foundation) of the responses of children to entertainment films, using infra-red 
photography. More recently, subliminal exposure to ciné-film has been used in the treatment of agoraphobia by Tyrer et al ${ }^{21}$ and Lee et al. ${ }^{22}$

The first attempt at the international cataloguing of mental health films was by Niewenhuize in 1952; subsequently nearly 700 films from sixteen countries were listed. ${ }^{33}$ The Royal Medico-Psychological Association formed a films sub-committec in 1957 and started appraising psychiatric films in association with the Scientific Film Association. The Mental Health Film Council (UK) was set up in 1962 and a Festival of Psychotherapy Films was organized in association with the Sixth international Congress on Psychotherapy in London. One of the winning films was about the treatment of psychiatric disorders in the Yoruba society in Nigeria. This exploration by film of the effects of culture on mental disorder was continued by the series of Film Festivals in Psychiatry held in San Antonio. Texas. from 1972 to 1976, reflecting, through film, the patterns in Switzerland, Mexico and Great Britain. It is significant that at a conference on audio-visual communication and mental health held some ycars latcr in Helsinki. the overwhelming concern was with the use of videotapes and broadcast television.

The production of tape-slide programmes in psychiatry has not developed to any extent. in contrast to many other medical disciplines. About 70 are listed by the Royal College of Psychiatrists. ${ }^{24}$ many of which are in essence recorded talks with very few slides. By contrast the growth in the use of videotapes for psychiatric teaching has been a phenomenon of the past decade. Over 100 such tapes distributed in the UK are listed by the College." and it is estimated that well over twice this number are in use but not made generally available for various reasons. The psychiatric potentials of broadcast TV were already apparent in The Hurt Mind series, shown over twenty years ago

In perspective this audio-visual material reflects the changing patterns of psychiatric treatment and care. In the 1920 s and 1930s, for example, the films were often descriptive and consisted of clinical records, in the 1940s and 1950s they tended to deal with physical methods of treatment and latterly with pharmacotherapy, and in the 1960s onwards many are concerned with aspects of care and treatment in the community. During this period when, for the first time. such audio-visual records have been made, there have also been significant changes in the style and technique of film making, and in conditions of viewing. Many of these films, although made with specific aims, also contain material giving significant and perhaps unexpected pointers to psychiatric practice over the past fifty years or so.

A large number of psychiatric films and films on aspects of mental health are now preserved in the British National Film Archives, and it is suggested that the systematic study of this material would give rewarding insights into the development of services, and fresh perspectives on current practice.

\section{RefERences}

'ANNEAR. M. W. (1968) The use of entertainment films in psychiatry and mental health lecture sessions. In Proceedings of the 20th World Congress. Washington: World Federation for Mental Health.

:GeSell, A. (ed) (1934) Atlas of Infant Behaviour. New Haven: Yale University Press.

${ }^{3}$ Lewin. K. (1935) Dynamic Theony of Personality. New York: McGraw. Hill

+Watson, J. B. (1921) Studies in infant psychology. Science Monitor. New York, 13, 493-96.

SGIL BRETH, F. B. (1913) Industrial management. Joumal of the American Sociery of Mechanical Engineers, 35, 871-73.

'Leighton, A. H. (1938) Catatonic Behaviour in a Deteriorated Schizo. phrenic Patient. (Film)

'Lehmann. H. (1952) Mental Symptoms. Numbers 1-9. (Films)

rPatterson. A. S. (1942) ECT and Electronarcosis. (Film. West London Hospital)

"Freeman, W. \& WatTs, J. W. (1942) Prefrontal Lobotomy in the Treat. ment of Mental Disorders. (Film)

10FitzGerald, O. \& Longinotto. M. (1944) Shock Treatment of Schizophrenia. (Film)

"Moreno, J. L. (1944) Psychodrama and therapeutic motion pictures. Sociometry, 7, 230-32.

I:MUller. C. \& BADER. A. (1968) The cinema and the mental patient: A new form of group therapy. Current Psychiarric Therapies. 8 , $169-72$

13PrADos, M. (195I) The use of films in psychotherapy. American Journal of Orthopsychiatry, 21, 1-4.

${ }^{14}$ Sprtz. R. A. (1947) Birth and the First Fifteen Minutes of Life. (Film. New York University Film Library)

15Roberison. J. (1952) A Two-Year-Old Goes to Hospital. (Film. British National Film Archives)

${ }^{16}$ Fulghum, C. B. \& PAsternack. B. S. (1960) A use of motion pictures in double-blind techniques. Psychopharmacologia. 1, 342-45.

${ }^{17}$ Cornelison. F. S. \& Arsenian. J. (1960) A study of the response of psychotic patients to photographic self-image experience. Psychiatric Quarterly (NY), 34, 1-8.

I'DuChe. D. J. \& Duvivier. E. (1960) Ballet on a Paraphrenic Theme. (Film)

19MEAD, M. (1951) Sibling Rivalry in Bali and New Guinea. (Film. New York University Film Library)

"LYNN. J. G. (1940) An apparatus and method for stimulating, recording and measuring facial expressions. Journal of Experimental Psychology, 27, 81-83.

${ }^{21}$ TYRER, P. J., HORN, S. \& LEE. I. (1978) Treatment of agoraphobia by subliminal and supraliminal exposure to phobic cine film. Lancet, 1, 358-60.

22LeE, I. Tyrer, P. J. \& Horn, S. (1983) A comparison of subliminal. supraliminal and faded phobic cine-films in the treatment of agoraphobia. British Joumal of Psychiatry, 143, 356-61.

iPilkington. T. L. (1962) World Menial Health Films. Washington: World Federation for Mental Health

${ }^{24}$ Royal College of Psychiatrusts (1984) Some tape-slides of teaching value. In Handbook for Psychiatric Tutors. Royal College of Psychiatrists.

25. (1984) Videotapes for psychiatric teaching. In Handbook for Psy. chiatric Tutors. Royal College of Psychiatrists. 